\title{
Hygro-thermal analysis of a flat roof structure integrating a variable vapor- diffusivity membrane
}

\author{
Riccardo Pinotti ${ }^{\mathrm{a}}$, Paola Brugnara ${ }^{\mathrm{b}}$, Stefano Avesani ${ }^{\mathrm{a}}$ \\ a Eurac Research, Bolzano, Italy \\ $b$ Rothoblaas srl, Cortaccia (BZ), Italy
}

\begin{abstract}
The work presented hereby aims at verifying the hygro-thermal performances of a non-ventilated timber frame flat roof structure integrating a variable vapor-diffusivity membrane. However, it is not a common approach to use this kind of membranes in roof structures since, in order to avoid condensation issues in the outer layer of the structure during cold season, vapor barriers or retarders are usually installed. Actually, this approach does not consider eventual criticalities occurring on the building site while installing these membranes, since the posing procedure may cause dangerous leakages for vapor within the structure. The variable vapor-diffusivity membrane can solve this issue behaving as a vapour retarder within typical relative humidity ranges, while becoming more vapor-open when surrounded by higher humidity values.
\end{abstract}

Peer-review under the responsibility of the organizing committee of the ICMB21.

Keywords: Dynamic hygro-thermal behaviour, Modeling and simulation, Membrane and timber-based construction

\section{Introduction/Background}

Vapor membranes are used to manage vapor transfer through the building structures. In fact, in typical continental climates, vaporretarder or barrier membranes are used to prevent high level of moisture to reach the outer layers of the envelope in order to avoid condensation issues during the cold season. However, the installation of vapor membranes is not always a smooth procedure to be performed on the building site. Small damages, scratches and imperfections during the laying of those membranes may be the cause of potentially critical one-way vapor leakages through the envelope, in particular if timber based. In this study, an alternative solution to the application of vapor retarders or barriers has been investigated, namely adopting an innovative variable vapordiffusivity membrane. Such membrane has the capability of varying its permeability to vapor, behaving as a vapor open layer when embedded in high moisture conditions hence, allowing a higher flexibility in the application procedure, ensuring a drying up potential to the structure containing high humidity levels. A detailed dynamic model of the construction has been setup and a set of simulations run to calculate the whole construction hygro-thermal performance under different climates, aiming at validating the use of such innovative layer.

\section{Methodology}

To access the performances of the proposed solution, a typical timber frame roof structure integrating a variable vapor-diffusivity membrane has been modelled in Delphin 6 and 10-years-long hygro-thermal simulations have been performed in different climatic conditions. The layer and material properties within the structure are described in Table 1.

Table 1 Structure layers and material properties

\begin{tabular}{|c|c|c|c|c|c|}
\hline Layer (from INSIDE to OUTSIDE) & Thickness & Density & Heat Capacity & Conductivity & Vapor Permeability \\
\hline & {$[\mathrm{mm}]$} & {$\left[\mathrm{kg} / \mathrm{m}^{3}\right]$} & {$[\mathrm{J} / \mathrm{kgK}]$} & {$[\mathrm{W} / \mathrm{mK}]$} & $\mathrm{Sd}[\mathrm{m}] \mu[-]$ \\
\hline Gypsum fiber Board & 12.5 & 744 & 1384 & 0.21 & $\mu=4$ \\
\hline Variable Vapour Diffusivity Membrane & Note 1 & Note 1 & Note 1 & Note 1 & $\mathrm{Sd}_{\text {variable }}=0.15 \div 5$ \\
\hline Mineral Wool Insulation & 240 & 110 & 1030 & 0.036 & $\mu=3.5$ \\
\hline OSB Panel & 20 & 530 & 1880 & 0.1 & $\mu=280$ \\
\hline $\begin{array}{l}\text { Self-Adhesive Bituminous Membrane } \\
\text { (Bytum Base 2500) }\end{array}$ & Note 1 & Note 1 & Note 1 & Note 1 & $S d=200$ \\
\hline Self-adhesive Slate Bituminous Membrane & Note 1 & Note 1 & Note 1 & Note 1 & $\mathrm{Sd}=280$ \\
\hline
\end{tabular}

$\underline{\text { Note } 1}$ Delphin does not require this parameter.

\footnotetext{
* Corresponding author. +390471055669 riccardo.pinotti@eurac.edu
} 
ICMB21

The roof structure has been tested in different climatic conditions which are reported in Table 2.

Table 2 Boundary Conditions tested

\begin{tabular}{|c|c|c|c|}
\hline Configuration & Layer structure used & T and RH INDOOR & T and RH OUTDOOR \\
\hline Condition 1 & Layer structure in Table 1 & $\begin{array}{c}\text { from WTA adaptive indoor climate model } \\
\text { implemented in Delphin6.0 }\end{array}$ & $\begin{array}{c}\text { Climatic condition: } \\
\text { München }\end{array}$ \\
\hline Condition 2 & $\begin{array}{c}\text { Layer structure in Table 1 + } \\
\text { (towards inside) } \mathbf{5} \text { cm insulation }+\end{array}$ & $\begin{array}{c}\text { from WTA adaptive indoor climate model } \\
\text { implemented in Delphin6.0 }\end{array}$ & $\begin{array}{c}\text { Climatic condition: } \\
\text { München }\end{array}$ \\
\hline Condition 3 fiber board & Layer structure in Table 1 & $\begin{array}{c}\text { from WTA adaptive indoor climate model } \\
\text { implemented in Delphin6.0 }\end{array}$ & $\begin{array}{c}\text { Climatic condition: } \\
\text { Brisbane }\end{array}$ \\
\hline Condition 4 & Layer structure in Table 1 & $\begin{array}{c}\text { from WTA adaptive indoor climate model } \\
\text { implemented in Delphin6.0 }\end{array}$ & $\begin{array}{c}\text { Climatic condition: } \\
\text { Abu Dhabi }\end{array}$ \\
\hline
\end{tabular}

\section{Results}

The total moisture content and relative humidity evaluated in the most critical layers of the structure have been evaluated. As an example, Figure 1, reports the 10-years trends for those quantities within the structure in Condition 1. It is possible to notice that, after 2 years, periodically moisture content peaks occur after winter season, and afterwards, the structure dries during warmer season. Moreover, relative humidity in the most critical layer (insulation-OSB interface) does not reach critical values for condensation (over-hygroscopic content expected with $\mathrm{RH}>95 \%$ ). On the other hand, testing the same structure in same Condition 1 , avoiding the use of the adaptive vapor-diffusivity membrane, brings to condensation within the structure, as shown in Figure 2.

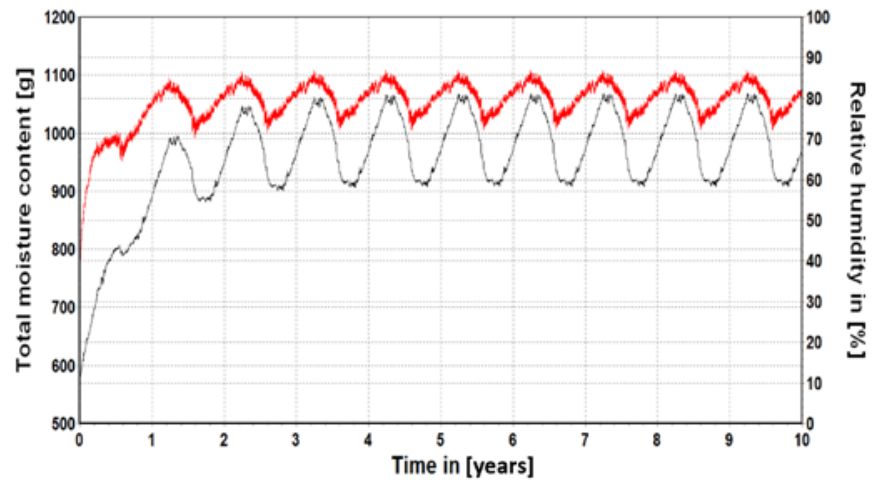

Figure 1 Total moisture content (black curve) and relative humidity Insulation/OSB interface (red curve) trends in Condition 1

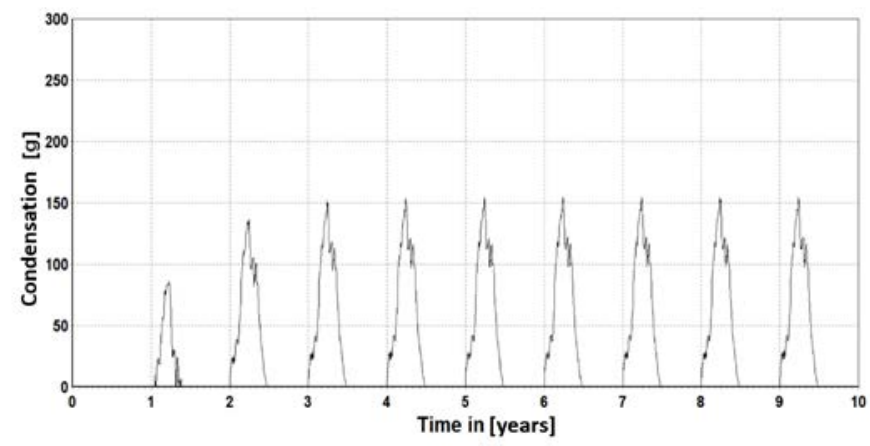

Figure 2 Periodical annual condensation Condition 1 WITHOUT variable vapor-diffusivity membrane

\section{Conclusions}

In all the tested conditions, the layer structure did not present any condensation issues (occurring conversely without such membrane). Hence, it can be claimed that the use of the variable vapor-diffusivity membrane can be a good solution in order to overcome eventual criticalities occurring during the application of membranes during the construction process. This confirms that the use of those membranes is able to avoid excessive humidity storage, allowing a sufficient drying of the structure during warmer season. Remarkable level of precision in the evaluation of the envelope performances can be reached replicating the modelling approach proposed in this study, also varying the boundary climatic conditions. 